Студенты из группы № 2 в соревновательных схватках смогли продемонстрировать достаточный уровень тактической подготовленности для идентификации их стилевой принадлежности. Полученные результаты позволяют сформулировать следующие выводы:

1. Отсутствие травматизма, стабильность численного показателя студентов, специализирующихся на учебных занятиях по физическому воспитанию в борьбе дзюдо, показывают высокую эффективность построения занятий по физическому воспитанию в ВУЗе, при котором широко используются тренировочные средства этого популярного у студенческой молодежи вида спорта.

2. Сравнение результатов двух исследуемых групп студентов, выявленных по показателям итогового тестирования, значительное увеличение уровня физической и технической подготовленности студентов, занимавшихся 3 раза в неделю по сравнению со студентами, посещавшими занятия 2 раза в неделю.

3. Значительное улучшение показателей физической и техно-тактической подготовленности в группе, занимающейся борьбой 3 раза в неделю. Позволяют рекомендовать введение в учебный процесс дополнительных занятий, а также развивать в ВУЗах массовый спорт как одно из наиболее эффективных средств воспитания студенческой молодежи.

$$
* * *
$$

1. Литвиненко А.Н. Эффективность применения средств спортивной подготовки единоборцев в физическом воспитании студентов технического ВУЗа («Отсутствие травматизма, стабильность численного показателя студентов, специализирующихся на учебных занятиях по физическому воспитанию в ВУЗе »). Физическое воспитание студентов. Харьковское областное отделение Национального олимпийского комитета Украины. -Харьков, 2013 г. С. 49-53.

2. Айгубов Н.М. теория и методика физического воспитания, спортивной тренировки, оздоровительной и адаптивной физической культуры. («Занятия дзюдо обладают значительным потенциалом для развития физических качеств, способствуют развитию систем организма, формированию навыков самообороны»). Журнал Научный поиск: Общество с ограниченной ответственностью «Технологический центр». - Шуя, 2012 г. С. 3-5.

3. Егоров Д.Е., Куликова И.В., Кутергин Н.Б. Единоборства в подготовке специалистов инженерного профиля. («Использование различных единоборств в учебном процессе позволяет умножить интерес к занятиям физической культурой и соответственно эффективность профессиональноприкладной подготовки»). Физическое воспитание и спорт в высших учебных заведениях: сб. статей VIII Международной научной конференции, 26-27 апреля 2012 г. БГТУ им. В.Г. Шухова. Белгород, 2012. С. 59-62.

\title{
Голубь И.Б. \\ Использование интерактивного стола или интерактивной доски в художественно- эстетическом развитии детей дошкольного возраста в совместной и индивидуальной деятельности
}

Приамурский государственный университет им Шолом-Алейхема (Россия, Биробиджан)

doi 10.18411/spc-04-03-2018-06

idsp 000001:spc-04-03-2018-06

\section{Аннотация}

В статье рассмотрены вопросы использования в образовательном процессе интерактивной доски или интерактивного стола. Специфика художественноэстетической деятельности дает широкие возможности для развития у детей дошкольного возраста эмоционально-эстетического отношения к действительности, конструкторских умений и накопление точных знаний об окружающей действительности.

Ключевые слова: художественно-эстетическая деятельность, дети дошкольного возраста, эмоциональное благополучие, творческое воображение. 
Научно-техническая революция стала основой процесса информатизации всех сфер жизни общества, в том числе и образования. В настоящее время в системе дошкольного образования происходят значительные перемены. Успех этих перемен связан с обновлением научной, методической и материальной базы обучения и воспитания. Одним из важных условий обновления является использование информационных технологий (ИКТ), в первую очередь, компьютеров.

Одной из главных задач современного образования является раскрытие способностей каждого ребенка, воспитание личности готовой к жизни в высокотехнологичном, конкурентном мире. Информатизация общества ставит перед педагогами-дошкольниками задачу стать для ребенка проводником в мир новых технологий, наставником в выборе компьютерных игр и сформировать основы информационной культуры личности ребенка. Использование информационнокоммуникационных технологий в детском саду становится все более актуальным и играет особую роль в развитии личности ребенка, т. к. позволяет в игровой, доступной и привлекательной для детей форме достигнуть нового качества знаний, стимулируя познавательную активность, развивая логическое мышление и творческие способности дошкольников. А знания, приобретенные при одновременном использовании аудио и видеоинформации, прочнее и сохраняются в памяти значительно дольше.

На сегодняшний день использование информационно-коммуникативных технологий является необходимым условием, так как главным становится не трансляция фундаментальных знаний, а развитие творческих способностей, создание возможностей для реализации потенциала личности. ИКТ используются не как цель, а как еще один педагогический инструмент, способствующий достижению поставленных целей.

Занятия с применением интерактивного стола или доски проводятся в ДОУ по всем направлениям: социально - коммуникативное, познавательное, речевое, художественно-эстетическое и физическое (формирование у дошкольников представлений о здоровом образе жизни). Суть таких занятий состоит в том, что практически все воспитанники оказываются вовлеченными в процесс познания, и каждый вносит в него свой особый индивидуальный вклад. Атмосфера доброжелательности и взаимной поддержки позволяет не только получать новые знания, но и развивает саму познавательную деятельность, переводит ее на более высокие формы кооперации и сотрудничества. А форма подачи материала соответствует тому способу восприятия информации, которым отличается новое поколение детей, у которых гораздо выше потребность в темпераментной визуальной информации и зрительной стимуляции.

Применение возможностей интерактивной доски позволяет педагогам:

* повысить качество образования детей за счет сочетания традиционных и интерактивных методов организации образовательной деятельности;

* представлять информацию в различной привлекательной для детей дошкольников форме (аудио, видео, анимация и т.д.), что обеспечивает максимальную наглядность изучаемого материала;

* активизировать процессы восприятия, мышления, воображения и памяти;

* мобилизовать внимание воспитанников;

* использовать различные цифровые образовательные ресурсы;

* проводить образовательную деятельность (совместную и самостоятельную) на высоком методическом уровне.

Использование интерактивного стола или доски в непосредственнообразовательной деятельности и индивидуальной с дошкольниками в ДОУ показало ряд преимуществ по сравнению с традиционными формами воспитания и обучения: 
* Представление информации на большом экране и возможность самим оперировать с изображенными предметами и объектами вызывает у детей огромный интерес к деятельности.

* Возможность представления фрагментов реальной действительности (видеоматериал).

* Возможность демонстрации детям движущихся, изменяющихся объектов, увеличивать размер изображения (например, книжных иллюстраций) в целях их комфортного восприятия всеми детьми группы;

* Одновременное воспроизведение объектов, представленных различными способами (звук-изображение-движение);

* Возможность проведения с объектами множества пробующих поисковых действий, сравнения нескольких вариантов преобразования одного и того же объекта;

* Экономия времени, необходимого для подготовки к занятиям и изучению конкретного материала, многократного применения используемого материала.

Получив первые навыки работы с интерактивным столом или доской в детском саду, дошкольники уверенно работают и в школе, применяя свои знания на новом уровне. Применение интерактивного стола в НОД так и в индивидуальной работе позволяет перейти от объяснительно-иллюстративного способа обучения детей к деятельностному, когда ребенок становится активным субъектом, а не пассивным объектом педагогического воздействия, что способствует осознанному усвоению необходимых знаний. Игровые компоненты, включённые в мультимедийные программы, активизируют познавательную активность детей и усиливают эффективность усвоения материала.

Игра на интерактивном столе - это продуктивная деятельность, направленная на получение результата из разнообразных элементов с использованием различных способов их соединения и взаимного расположения частей.

Занятия на интерактивном столе или доске в детском саду имеют свою специфику, они должны быть эмоциональными, яркими, с привлечением большого иллюстративного материала, с использованием звуковых и видеозаписей. В непосредственно - образовательной деятельности ИКТ используется как часть занятия, в соответствии с возрастом детей и требованиями Санитарных правил. Педагоги детского сада активно используют в своей работе мультимедийные средства интерактивный стол, интерактивная доска, что позволяет моделировать различные ситуации;

- активизирует внимание дошкольников благодаря возможности демонстрации явлений и объектов в динамике;

- способствует лучшему усвоению материала, так как в этот процесс, включаются все каналы восприятия детей - зрительный, механический, слуховой и эмоциональный;

- полученные знания остаются в памяти на более долгий срок и легче восстанавливаются для применения на практике после краткого повторения;

- занятия - презентации вызывают большой интерес у ребят, надолго привлекают внимание. Задача разного рода слайд-шоу и видеофрагментов - показать детям те моменты из окружающего мира, наблюдение которых непосредственно вызывает затруднения.

Художественное творчество для детей является любимым занятием, особенно если они создают его по собственному замыслу; предложенная же педагогом тема зачастую не вызывает широкого отклика у дошкольника. Потому современному педагогу вовлечь ребенка в процесс обучения становится все труднее. 
Например, при погружении в лексическую тему «Овощи» при организации НОД дети с удовольствием отгадывали загадки передвигая нужные картинки (ответы). При организации НОД по ХЭР рассматривают элементы хохломской росписи (рисование) решаются задачи развитие основ визуальной культуры, представление информации в образном плане, в привычной для современных детей форме (закрашивание предметов определенным цветом, увеличение или уменьшение размера, превращение квадрата в прямоугольник или треугольник. При организации НОД по конструированию используется игра «Фантазеры» где дети практически закрепляют ранее полученные знания, игра «Назови правильно» - дети самостоятельно из геометрических фигур создают определенный объект, все вместе они должны собрать из деталей дом, но каждый по очереди может взять только одну деталь; - один ребенок у доски выполняет задание под руководством группы детей, которые по очереди руководят его действиями; или, ребенок выполняет задание - нарисовать по клеточкам симметрично вторую половинку предмета; какой взять лепесток и с какой стороны подсоединить к серединке цветка). Дети среднего и старшего дошкольного возраста очень любят выполнять задания по изготовлению атрибутики к сюжетно-ролевым играм (билетики), так же самостоятельно выполнять задания по типу раскрасок «Дорисуй картинку», «На что похоже?», «Составь картинку» и т.п. Данное оборудование позволяет создавать мультимедийные презентации и мультимедийных персонажей, которые с экрана вовлекают детей в образовательную деятельность, позволяя педагогу играть вместе с детьми (Путешествие кубика (изучение геометрических фигур, порядковый и количественный счет).

При использовании интерактивной доски на занятии, дети, не работающие непосредственно у доски, выполняют аналогичное задание за столами или мольбертами на бумажном носителе. Использование таких разнообразных форм организации работы детей с интерактивной доской снимает ряд проблем, которые могут возникнуть при применении ИКТ в образовательной работе с дошкольниками, таких как утомление, нервно-эмоциональное напряжение и отказ от коммуникативных отношений. Постоянная смена деятельности при выполнении различных заданий, работа парами, подгруппой способствует развитию общения и взаимодействия со сверстниками, формированию способности к совместной деятельности. Дети с большим удовольствием работают на интерактивной доске, быстро осваивая все ее возможности и способы работы различными средствами.

Проблема, которая может возникнуть при использовании интерактивной доски в образовательном процессе, это профессиональная компетентность педагогов - умение не только пользоваться современной техникой, но и создавать собственные образовательные ресурсы, быть грамотным пользователем сети Интернет.

При правильно организованной деятельности дети приобретают:

1. Конструктивно-технические умения

- сооружать отдельные предметы из строительного материала - здания, мосты и т.д.

- собирать картинки - изменяя цвет, размер и т.д.

2. Обобщенные умения

- целенаправленно рассматривать предметы,

- сравнение предметов между собой и расчленение их на части;

- развитие умения находить основные конструктивные части, от которых зависит расположение других частей;

- развитие умения делать выводы и обобщения.

Особое значение в развитии художественно-эстетической деятельности имеет мышление детей, так как именно художественная деятельность носит практическую направленность и творческий характер. При погружении детей в художественную 
деятельность развивается планирующая мыслительная деятельность, что является важным фактором при формировании учебной деятельности.

Данная деятельность способствует практическому познанию свойств геометрических тел и пространственных отношений:

- речь детей обогащается новыми терминами, понятиями (брусок, куб, пирамида и др.)

- дети упражняются в правильном употреблении понятий (высокий низкий, длинный - короткий, широкий - узкий, большой - маленький), в точном словесном указании направления (над - под, вправо - влево, вниз - вверх, сзади - спереди, ближе и т.д.).

«Художестве6нно-эстетическая деятельность - процесс дыхания души» отмечал Василий Кандинский. Следовательно - это не столько фактическая передача увиденного, сколько выражение своих чувств, эмоций, психологическая разгрузка средство самораскрытия. А ребёнку очень важно иметь возможность свободно выражать свой внутренний мир. Для него создание - это своеобразный способ общения с внешним миром. Посредством данного процесса он может выразить свою радость или боль, свои страхи, вопросы, фантазии, своё отношение к окружающим.

Большой потенциал для развития детского творческого мышления заключен в конструктивной деятельности. Обратившись к последним исследованиям педагогов Г.Г. Григорьевой, Т.С. Комаровой, Ц.П. Короленко (Л.Ю. Субботиной, А.М. Страунинг, Т.В. Фроловой), стало ясно, что среди методов приобщения дошкольников к конструктивному творчеству актуальными в формировании творческого мышления следуют приемы, разработанные на основе теории решения конструктивных задач (конструктивные игры). Именно конструирование в ИКТ в сочетании с игрой и другими средствами эмоционального воздействия на ребенка (музыка, художественное слово, пантомимика, живопись и др.) оказывают благотворное влияние на развитие творческого мышления дошкольников, что, в свою очередь, ведет к возникновению необычных, оригинальных образов и композиций.

Художественно-эстетическая деятельность является также средством нравственного воспитания дошкольников. В процессе этой деятельности формируются качества личности:

- трудолюбие,

- самостоятельность,

- инициатива,

- упорство при достижении цели,

- организованность.

Совместная художественная деятельность детей на интерактивной доске играет большую роль в воспитании первоначальных навыков работы в коллективе:

- умение предварительно договариваться (распределять обязанности, отобрать материал необходимый для достижения запланированного результата)

- работать дружно, не мешая друг другу.

Следовательно, применение информационных технологий в художественноэстетическом развитии детей способствует:

- развитию основ визуальной культуры;

- представлению информации в образном плане за счет мультимедиаэффектов в «привычной» для современных детей форме;

- познанию в процессе экспериментирования и игры; переносу акцентов с «информационных» методов на «демонстрационные», что соответствует сути искусства, идеям эстетического развития и возрастным возможностям дошкольников. 
Таким образом, использование интерактивных средств в художественноэстетическом воспитании дошкольника позволяет не только обогащать знания, но и более полно знакомить с окружающим, находящимися за пределами собственного опыта ребенка. Способствует хорошей результативности занятия. Помогает повышать креативность, умение оперировать символами на экране монитора, способствует оптимизации перехода от наглядно-образного к абстрактному мышлению. Использование интерактивных средств в образовательном процессе, помогает педагогу развивать и формировать поисково-исследовательскую деятельность, не только у детей, но и их родителей, включая Интернет-ресурсы.

$$
* * *
$$

1. Изобразительная деятельность в детском саду. Комарова Т.С., 2015

2. Примерная основная образовательная программа образовательного учреждения. Основная школа / [сост. Е.С. Савинов]. — М.: Просвещение, 2011. - 454 с.

3. У Ушнский К.Д. Избранные педагогические соч., т. 1-2, М., 1974.- 401 с.

4. Ананьева И.И., Евтух Е.В. Интерактивная доска как новый инструментарий учителя музыки: методические рекомендации. - СПб АППО, 2010.-100с.

5. Ермолаева М.Г. Современный урок: анализ, тенденции, возможности: Учебно-методическое пособие. - СПб.: КАРО, 2011.-160с.

\section{Конова Т.А., Гуреева Н.В., Шемякина И.Е. Возможности и условия совершенствования учебной деятельности}

Тюменское высшее военно-инженерное командное училище имени маршала инженерных войск А.И. Прошлякова (Россия, Тюмень)

doi 10.18411/spc-04-03-2018-07

idsp 000001:spc-04-03-2018-07

Приоритетное направление развития образования в настоящее время направлено на усиление практической составляющей обучения уже начиная с первых курсов. Это связано с тем, что самым слабым местом традиционного обучения является пассивность обучающихся при высокой односторонней активности преподавателя. Поэтому в последнее время педагогами разных образовательных организаций разрабатываются новые формы подачи материала, способствующих активизации работы обучающихся на занятиях. В их числе проблемная лекция, лекцияконсультация, лекция пресс-конференция, интерактивные практические занятия, семинары, конференции. Безусловно это способствует повышению уровня знаний обучающихся, но не активизирует мотивацию к совершенствованию.

Нами выдвинута гипотеза, что совершенствование учебной деятельности возможно при сочетании ряда условий: качественная подготовка профессорскопреподавательского состава; внедрение результатов научно-исследовательской деятельности в учебный процесс; проведение педагогических экспериментов, с внедрением в учебный процесс результатов исследования; интеграция образовательной и научной (научно-исследовательской) деятельности.

Самообразование педагога сложный многофакторный процесс, который не ограничивается только курсами повышения квалификации и чаще всего приносит больший результат в процессе выполнения индивидуальных научно-исследовательских заданий и использованием их результатов в образовательной деятельности. Так, в настоящее время, на кафедре ведутся научно-исследовательские работы, непосредственно связанные с изучением и разработкой рекомендаций по совершенствованию образовательного процесса (таблица 1). 